\title{
The effect of dexmedetomidine on propofol injection pain
}

\author{
Jeong Han Lee, Soon Yong Jung, Myoung-Hun Kim, and Kwangrae Cho \\ Department of Anesthesiology and Pain Medicine, Busan Paik Hospital, Inje University College of Medicine, Busan, Korea
}

Propofol causes pain during vascular injection. Dexmedetomidine, an $\alpha_{2}$-adrenoceptor agonist, has an analgesic effect as well as a sedative effect. Several studies have examined whether the analgesic effect of dexmedetomidine can reduce pain associated with propofol injection [1], but these studies were not helpful in clarifying the appropriate dosage of dexmedetomidine for minimizing hemodynamic changes from the drug while maximizing the reduction of propofol injection pain. In this study, we evaluated the efficacy of dexmedetomidine in reducing pain and hemodynamic changes during propofol injection.

The study was approved by the Institutional Review Board of our hospital, and informed consent was obtained from the subject patients after sufficient explanation regarding general anesthesia and our study. One hundred sixty American Society of Anesthesiologists physical status 1 or 2 patients (20 to 60 years old) who were scheduled for elective surgery were enrolled. They were randomly divided into four groups; group 1 (propofol 120 $\mathrm{mg}$ and normal saline, $\mathrm{n}=40$ ), group 2 (propofol $120 \mathrm{mg}$ and dexmedetomidine $0.25 \mu \mathrm{g} / \mathrm{kg}, \mathrm{n}=40$ ), group 3 (propofol $120 \mathrm{mg}$ and dexmedetomidine $0.5 \mu \mathrm{g} / \mathrm{kg}, \mathrm{n}=40$ ), and group 4 (propofol $120 \mathrm{mg}$ and dexmedetomidine $0.75 \mu \mathrm{g} / \mathrm{kg}, \mathrm{n}=40$ ). The volume of the drug mixture 1\% propofol (long-chain triglyceride) and saline or dexmedetomidine was $15 \mathrm{ml}$ in all patients. Injection pain was graded using a 4-point scale. A 20 gauge catheter was mounted on the dorsal hand or wrist area. The drug mixture was injected for 25 seconds through the catheter in order to induce anesthesia. From the start of the injection until the loss of consciousness, each patient was asked, "Does it hurt?" every 5 seconds to measure the degree of pain. The pain was evaluated as 0 when there was no discomfort in the injection area (no pain), 1 when the patient simply answered "Yes" without any change in behavior (slight), 2 when there was a change in behavior or voluntary complaint of pain (intermediate), and 3 when the patient made a loud sound, grimaced, withdrew his or her arm, or shed tears (severe). SAS 9.2 (SAS Institute Inc., Cary, NC, USA) was used to perform a one way ANOVA for age, height, weight, and hemodynamic changes. The degree of pain was analyzed with a $\chi^{2}$-test, and the results were considered statistically significant

Table 1. Incidence of Pain after Administration of Propofol and Dexmedetomidine

\begin{tabular}{|c|c|c|c|c|}
\hline & \multicolumn{4}{|c|}{ Pain score } \\
\hline & 0 & 1 & 2 & 3 \\
\hline Group $1(n=40)$ & $10(25)$ & $13(32.5)$ & $17(42.5)$ & $0(0)$ \\
\hline Group $2(n=40)$ & $10(25)$ & $23(57.5)^{*}$ & $7(17.5)^{*}$ & $0(0)$ \\
\hline Group $3(n=40)$ & $19(47.5) *, \dagger$ & $19(47.5)^{*}$ & $2(5)^{*}$ & $0(0)$ \\
\hline Group $4(n=40)$ & $20(50)^{*, \dagger}$ & $19(47.5)^{*}$ & $1(2.5)^{*}$ & $0(0)$ \\
\hline
\end{tabular}

Values are number of patients (\%). Group 1: propofol $120 \mathrm{mg}+$ saline, Group 2: propofol $120 \mathrm{mg}+$ dexmedetomidine $0.25 \mu \mathrm{g} / \mathrm{kg}$, Group 3: propofol $120 \mathrm{mg}+$ dexmedetomidine $0.5 \mu \mathrm{g} / \mathrm{kg}$, Group 4: propofol $120 \mathrm{mg}+$ dexmedetomidine $0.75 \mu \mathrm{g} / \mathrm{kg}$, Pain score: 0 (no pain), 1 (slight), 2 (intermediate), 3 (severe). ${ }^{*} \mathrm{P}<0.05$ compared with group $1,{ }^{\dagger} \mathrm{P}<0.05$ compared with group 2.

Corresponding author: Jeong Han Lee, M.D., Ph.D., Department of Anesthesiology and Pain Medicine, Busan Paik Hospital, Inje University College of Medicine, 75, Bokji-ro, Busanjin-gu, Busan 614-735, Korea. Tel: 82-51-890-6520, Fax: 82-51-898-4216, E-mail: 1jh646@inje.ac.kr (c) This is an open-access article distributed under the terms of the Creative Commons Attribution Non-Commercial License (http:// creativecommons.org/licenses/by-nc/3.0/), which permits unrestricted non-commercial use, distribution, and reproduction in any medium, provided the original work is properly cited. 
when the P value was less than 0.05 . Demographic characteristics were similar among the patient groups. The incidence of injection pain diminished significantly in group 3 (52.5\%) and group 4 (50\%) compared with group 1 (75\%) and group 2 (75\%), while there was no significant difference between groups 3 and 4 (Table 1). By measuring hemodynamic changes before and after the drug injection, it was found that the heart rate significantly decreased in groups 2 (16.7\%), 3 (22.7\%), and 4 (26.7\%) compared with group $1(8.7 \%)(\mathrm{P}<0.05)$. The decrease in systolic and diastolic blood pressure was smaller in groups 2 (6.2 and $5.2 \%)$ and 3 (6.8 and 1.3\%) compared with group 1 (19.9 and $12.3 \%)(\mathrm{P}<0.05)$, while the systolic and diastolic blood pressure increased in group $4(0.7$ and $7.7 \%)(\mathrm{P}<0.05)$. There was a significant difference in diastolic blood pressure change between group 2 and group $4(\mathrm{P}<0.05)$.

Dexmedetomidine has an analgesic effect by controlling the nociceptive signal transmission at both the central nervous system of the supraspinal and spinal levels, while accelerating antinociception in the periphery. Although the precise mechanism for this acceleration has not been discovered, possible mechanisms include antinociception accelerated through an inwardly rectifying hyperpolarization-activated conductance [2] or through an $\alpha_{1}-, \alpha_{2}-$ stimulation, causing the release of vasodilator prostaglandins that control the sympathetic response of the venous smooth muscles [3]. In the research of Turan et al. [1], the forearm was pressurized with a tourniquet at $70 \mathrm{mmHg}$ and dexmedetomidine, $0.25 \mu \mathrm{g} / \mathrm{kg}$, was administered. Then, the venous flow was blocked for 20 seconds with the tourniquet and $5 \mathrm{ml}$ of propofol was injected at a speed of $20 \mathrm{mg} / \mathrm{sec}$ for 5 seconds. They reported that this method showed a pain reduction effect similar to that achieved through pre-medicating with lidocaine, $0.5 \mathrm{mg} / \mathrm{kg}$, using the same method. Erdil et al. [4] injected saline or dexmedetomidine $0.6 \mu \mathrm{g} / \mathrm{kg}$ for 10 minutes before injecting $1 \%$ propofol $2.5 \mathrm{mg} / \mathrm{kg}$, at a speed of $10 \mathrm{mg}$ per 5 seconds. They reported that the pain score was lower in the group that received dexmedetomidine. In our study, the groups that received dexmedetomidine $0.5 \mu \mathrm{g} / \mathrm{kg}$ and $0.75 \mu \mathrm{g} / \mathrm{kg}$, experienced a significant reduction in propofol injection pain similar to the reduction reported by Erdil et al. [4], who used $0.6 \mu \mathrm{g} / \mathrm{kg}$. When considering the results of precedent studies and the present study in conjunction, a reliable effect can be expected with a dosage of $0.5 \mu \mathrm{g} / \mathrm{kg}$ or higher when using dexmedetomidine to reduce propofol injection pain. The increase in blood pressure seen during dexmedetomidine administration is due to vasoconstriction of the $\alpha_{2} \mathrm{~B}$-adrenoceptor, which is located on the smooth muscle cells of certain peripheral blood vessels [5]. The decline in heart rate is attributable to the baroreceptor reflex response to the increase in blood pressure. In this study, there were smaller decreases in blood pressure in all groups that were administered dexmedetomidine $(0.25-0.75 \mu \mathrm{g} / \mathrm{kg})$ compared to saline administration. The reason for this is unclear, but considering the marked decrease in blood pressure seen in the saline group, the blood pressure increasing effect of dexmedetomidine may be a counterbalance to the blood pressure decreasing effect of propofol. In conclusion, this study shows that $0.5 \mu \mathrm{g} / \mathrm{kg}$ of dexmedetomidine mixed with propofol is a proper dosage for reducing injection pain while controlling hemodynamic changes.

\section{References}

1. Turan A, Memis D, Kaya G, Karamanlioglu B. The prevention of pain from injection of propofol by dexmedetomidine and comparison with lidocaine. Can J Anaesth 2005; 52: 548-9.

2. Dalle C, Schneider M, Clergue F, Bretton C, Jirounek P. Inhibition of the I(h) current in isolated peripheral nerve: a novel mode of peripheral antinociception? Muscle Nerve 2001; 24: 254-61.

3. Callow ID, Campisi P, Lambert ML, Feng Q, Arnold JM. Enhanced in vivo alpha1- and alpha2-adrenoceptor-mediated venoconstriction with indomethacin in humans. Am J Physiol 1998; 275: H837-43.

4. Erdil FA, Gulhas N, But AK, Begec Z, Ersoy MO. Does single dose premedication of dexmedetomidine reduce pain during injection of propofol? The Pain Clinic 2007; 19: 21-5.

5. Bloor BC, Ward DS, Belleville JP, Maze M. Effects of intravenous dexmedetomidine in humans. II. Hemodynamic changes. Anesthesiology 1992; 77: 1134-42. 